\title{
Rhegmatogenous retinal detachment in children 16 years of age or younger
}

This article was published in the following Dove Press journal:

Clinical Ophthalmology

15 June 2013

Number of times this article has been viewed

\author{
Sultan AL-Zaaidi' \\ Saba AL-Rashaed ${ }^{2}$ \\ Essam AL-Harthi ${ }^{3}$ \\ Eman AL-Kahtani ${ }^{2}$ \\ Ahmed M Abu El-Asrar ${ }^{4}$ \\ 'Prince Sultan Medical Military City, \\ Riyadh, Saudi Arabia; ${ }^{2}$ King Khaled \\ Eye Specialist Hospital, Riyadh, Saudi \\ Arabia; ${ }^{3} \mathrm{AL}-\mathrm{H}$ okama Eye Center, \\ Riyadh, Saudi Arabia; ${ }^{4}$ King Abdul \\ Aziz University Hospital, King Saud \\ University, Riyadh, Saudi Arabia
}

Purpose: To study the anatomical and visual outcomes and prognostic factors that may predict the outcomes of rhegmatogenous retinal detachment (RRD) in children.

Methods: A retrospective chart review was performed for patients 16 years of age or younger who underwent retinal reattachment surgery for RRD at the King Abdulaziz University Hospital from 1996 to 2005 and the King Khalid Eye Specialist Hospital from 2002 to 2006, Riyadh, Saudi Arabia. Good visual outcome was defined as $\geq 20 / 200$. The association between two categorical variables was evaluated with the Chi-squared test or the exact test, as appropriate. Predictors for RRD and good final visual acuity were identified by conducting stepwise logistic regression analysis. $P<0.05$ was statistically significant.

Results: The study population comprised 148 patients (166 eyes). There were 104 (70\%) males and $44(30 \%)$ females. Mean age at presentation was $8.33 \pm 3.26$ years (range $1.5-16$ years). The retina was reattached after one surgical procedure in $106(63.8 \%)$ eyes and reattached in 130 $(78.3 \%)$ eyes after multiple surgeries. Factors predicting recurrence after the first surgery were myopia ( $P=0.028)$, proliferative vitreoretinopathy $(\mathrm{PVR})$ at presentation $(P=0.024)$, and total retinal detachment $(P=0.032)$. Good final visual outcome was achieved in $60(44.4 \%)$ eyes. Predictors of good visual acuity were: good visual acuity at presentation $(P<0.001)$; absence of PVR at presentation $(P<0.001)$; one quadrant of retinal detachment $(P=0.0024)$; macula on $(P=0.0107)$; absence of primary repair of a ruptured globe $(P=0.0059)$; no pars plana vitrectomy (PPV) $(P=0.0123)$; clear phakic lens at follow-up $(P<0.001)$; absence of postoperative complications $(P<0.001)$; absence of recurrence of $\operatorname{RRD}(P<0.001)$; and absence of epiretinal membrane $(P=0.0088)$. Logistic regression analysis indicated that recurrence of RRD was associated with myopia and previous congenital cataract surgery; good final visual outcome was associated with macula on detachment and poor visual outcome was associated with recurrence of RRD and occurrence of postoperative complications and previous repair of a ruptured globe.

Conclusion: RRD in children is usually associated with a predisposing factor, a high rate of PVR, and total retinal detachment. Despite late diagnosis and the presence of PVR, favorable anatomical and visual outcomes can be achieved.

Keywords: children, rhegmatogenous, retinal detachment, predisposing factors, outcome

\section{Background}

Retinal breaks are present in 5\%-10\% of the general public; however, very few lead to rhegmatogenous retinal detachment (RRD). In the general population, the estimated incidence of RRD is one in 10,000. After an RRD in one eye, the risk of RRD is approximately $10 \%$ in the fellow eye. Pediatric retinal detachment has been reported in numerous studies. ${ }^{1-38}$ The incidence of pediatric retinal detachments
Correspondence: Sultan AL-Zaaid Prince Sultan Medical Military City, PO Box 365674, Riyadh, I I393, Saudi Arabia

Tel +966 | | 477 77| 4 ext 25702

Email alzaaidi_s@yahoo.com 
is low, accounting for approximately $1.7 \%-5.9 \%$ of all retinal detachments. ${ }^{2-8}$ There is a greater preponderance of pediatric retinal detachment in males $(70 \%-79 \%$ of all cases). The most common type of retinal break is a horseshoe tear. ${ }^{7}$

Etiological factors for RRD in children include congenital or structural abnormalities, trauma, myopia, previous ophthalmic surgery, and a positive family history. ${ }^{13}$ Congenital and developmental structural abnormalities play a major role in the pathogenesis of pediatric RRD, and may be more common than previously reported. ${ }^{7-16,35-38}$ Associations have been reported for familial exudative vitreoretinopathy, congenital retinoschisis, Coats' disease, retinopathy of prematurity, ${ }^{26-28,38}$ Marfan syndrome, Stickler syndrome, ${ }^{29-31}$ morning-glory disk anomaly, ${ }^{24}$ retrolental fibroplasia, X-linked retinoschisis, CHARGE (syndrome of colobomatous microphthalmia, heart defects, choanal atresia, retarded growth, genital abnormalities, and ear abnormalities), Sturge-Weber syndrome, retinoblastoma, microspherophakia, buphthalmos, neurofibromatosis type $\mathrm{I},{ }^{9}$ and mental and growth retardation were reported. ${ }^{1-16}$ Traumas, as well as congenital and developmental anomalies, are also associated with myopia. ${ }^{1-12}$

Trauma has been reported as the major cause of RRD in children worldwide. Blunt, penetrating, or high-velocity objects, and surgical iatrogenic trauma or surgical procedures for congenital cataract, cryotherapy, or laser photocoagulation in retinoblastoma, retinopathy of prematurity, ${ }^{24}$ and other procedures have also been implicated as a cause of RRD. ${ }^{7-16}$ Retinal detachment secondary to child abuse was first reported by Kiffney. ${ }^{17}$

The outcome of surgical repair in pediatric RRD depends on etiology, the chronic nature of the RRD, and the intended procedure. Selection of the surgical procedure can be limited, especially when considering the type of tamponade. Silicone oil is more reliable than gas, because of the difficulties in keeping a child in one position for a prolonged period of time. Reoperation may be dependent on etiology, surgical procedure technique, and intra- or postoperative complications.

The most common complication after surgical repair of RRD is proliferative vitreoretinopathy (PVR). Khvatova et $\mathrm{al}^{34}$ reported on 55 eyes that had undergone reoperation for RRD, and stated that the efficacy of the surgical treatment depends on the origin of the disease and the severity of the PVR. In the current study, we investigate the anatomical and visual outcomes and prognostic factors that may predict outcomes of RRD in children.

\section{Patients and methods}

Approval to conduct the study from the Research and Medical Ethics Committees at King Khalid Eye Specialist Hospital was granted for this study. The patient charts were identified for the 5 consecutive years (January 2001-December 2005) under study and reviewed. At King Abdul-Aziz University Hospital, ethics approval from the Ophthalmology Department was obtained. The patient charts and the surgical logbooks for 10 consecutive years spanning January 1995 to December 2004 were reviewed.

To be included in the study, patients had to be 16 years old or younger and had undergone surgical repair for RRD and completed 1 year of follow-up. The data-collection sheet was designed to collect parameters based on a current literature review. The data collected included patient age, sex, complaints, duration of symptoms, previous ophthalmic history, history of trauma, history and details of previous ophthalmic surgery, eye affected, ocular family history, visual acuity (VA) at presentation (preoperatively) and at last postoperative visit, intraocular pressure (IOP) at presentation, refractive error or spectacle prescription, strabismus, lens and vitreous status, extent of retinal detachment and status of the macula, presence of PVR, type and location of retinal holes and breaks, dialysis, and peripheral retinal changes. Data were collected for both eyes. The type of surgical procedure and operative notes were reviewed, including examination under anesthesia, type of procedure, and tamponade.

Data were collected for postoperative complications and management, with specific attention to the recurrence of RRD. Final anatomical and visual outcomes were analyzed and evaluated for presenting symptoms, procedures, complications, and number of surgeries performed.

\section{Statistical methods}

All data were manually entered into the data-collection sheet, then digitally entered and analyzed. The association between two categorical variables was investigated using either the Chi-squared test or the exact test as appropriate. Two proportions from the same sample were compared using Student's $t$-test. $P<0.05$ was considered statistically significant.

Predictor variables for RRD and good final VA of $20 / 200$ or better were identified by conducting stepwise logistic regression analysis. In this analysis, all variables that were investigated as risk factors for RRD and final VA in univariate analysis were included as significance of a selected predictor variable and judged by computation of $95 \%$ confidence intervals (CIs) around the odds ratio 
(OR) for that variable. CIs that did not include a value of 1.0 indicated statistical significance. Statistical analyses were performed with SPSS version 13 (IBM, Armonk, NY, USA), StatsDirect (Altrincham, UK) and BMDP 2007 (Statistical Solutions, Saugus MA, USA) software.

\section{Results}

A total of 668 patient charts were reviewed, of which only 166 eyes of 148 patients fitted the inclusion criteria. There were 104 $(70 \%)$ males and $44(30 \%)$ females $(\mathrm{M}: \mathrm{F}=2.36)$ (Figure 1). The age at presentation was $8.33 \pm 3.26$ years (range 1.25-16 years). Right and left eyes were equally affected. Mean follow-up was $40.14 \pm 27.06$ months (range 12-156 months). The mean duration of symptoms was $5 \pm 277$ days (range 1-1460 days), and the median was 17 days. Presenting symptoms varied from being asymptomatic (ie, incidental finding in routine exam or follow-up) in $38(23 \%)$ eyes, floaters in three $(1.8 \%)$ eyes, decrease or loss of vision in $76(45.7 \%)$ eyes, traumatic globe injury in $16(9.6 \%)$ eyes, and shrunken globe in two (1.2\%) eyes (Figure 2).

Ocular history showed $45.18 \%$ of patients with multiple predisposing factors. Seventy-two (43.3\%) eyes had a history of trauma, 51 (30.7\%) eyes were myopic, 29 eyes (17.5\%) had a history of cataract surgery, and 13 eyes $(7.8 \%)$ had a history of surgery for congenital glaucoma. There was a history of globe-rupture repair in $26(15.7 \%)$ eyes, retinopathy of prematurity and history of preterm delivery in six (3.6\%) eyes, previous retinal reattachment surgery in $16(9.6 \%)$

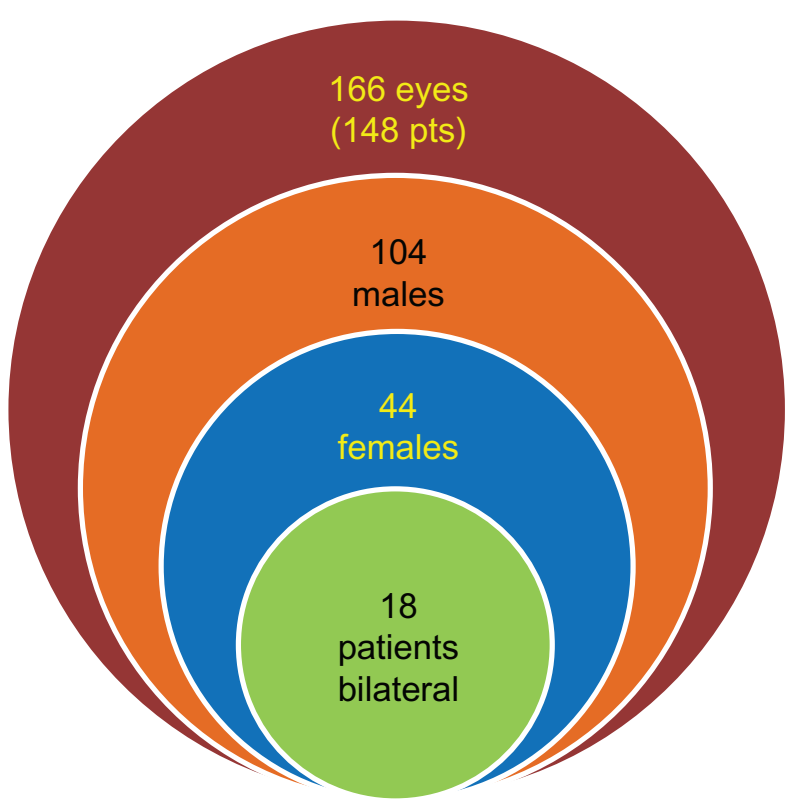

Figure I Patient demographics of children who presented with rhegmatogenous retinal detachment.

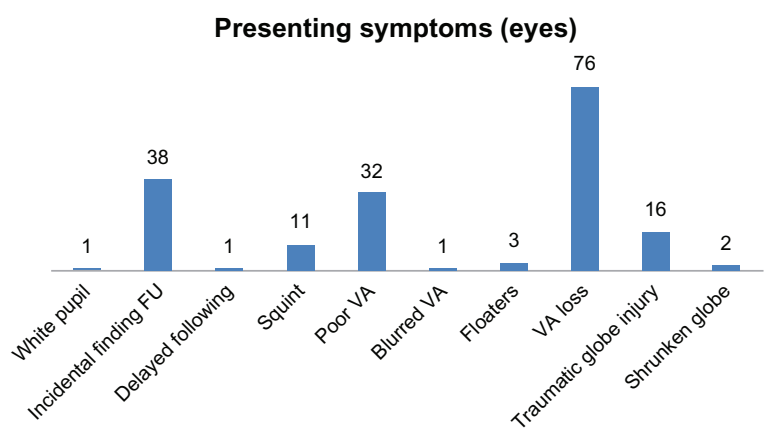

Figure 2 Presenting symptoms of children with rhegmatogenous retinal detachment. Abbreviation: VA, visual acuity.

eyes, and no previous ocular history in 24 (14.45\%) eyes. Seventeen (10.2\%) eyes had a family history of retinal reattachment surgery (Figure 3).

Ophthalmic, congenital, and developmental associations were found in $31 \%$ of the patients. These associations included Stickler syndrome in $26(15.6 \%$; bilateral in four patients) eyes, choroidal coloboma in five $(3 \%)$ eyes, and microphthalmia in three $(1.8 \%)$ eyes (Table 1$)$. One $(0.6 \%)$ eye presented with RRD associated with high IOP (Schwartz's syndrome), and one $(0.6 \%)$ eye presented with RRD, choroidal detachment, and severe hypotony (Table 1).

At presentation, VA was measured in 151 (91\%) eyes. Presenting VA ranged from $20 / 20$ in two (1.2\%) eyes to light perception (LP) in 27 (16.27\%) eyes. Presenting VA was grouped into VA $\geq 20 / 200$, Counting Fingers (CF), and no light perception (NLP)/LP-hand motion (HM). Thirty-six (23.7\%) eyes had $\geq 20 / 200$ at presentation, 52 (31\%) eyes presented with CF, and 58 (35\%) eyes had VA of LP-HM. In 15 eyes of younger children where VA charts were not applicable, ten $(6 \%)$ eyes were able to fixate and follow, and five $(3.3 \%)$ eyes had poor fixation. Twenty-five (15\%) eyes had strabismus preoperatively.

Refraction was documented in 73 (44\%) eyes, with mean spherical equivalent preoperatively $-5.07 \pm 10.20 \mathrm{D}$ (range -24 to $14.5 \mathrm{D}$ ); the median was $-7.25 \mathrm{D}$. Fifty-one (30.7\%) eyes were myopic (Figure 4), and 21 (12.6) eyes were hyperopic. Myopic eyes were divided into eyes with a spherical equivalent of $-6 \mathrm{D}$ or less (low myopia; eleven [6.6\%] eyes) and spherical equivalent greater than $-6 \mathrm{D}$ (high myopia; 40 [24\%] eyes). In the high-myopia group, the mean spherical equivalent was $-13.1 \pm 4.49 \mathrm{D}$ (range -6 to -24 D), with a median of -13 D. Figure 5 highlights some features of the myopia group. Figure 6 shows the lens status in the hyperopic group.

Seven $(46.7 \%)$ of the myopic eyes with no other associated pathology had a recurrence of RRD postoperatively, 


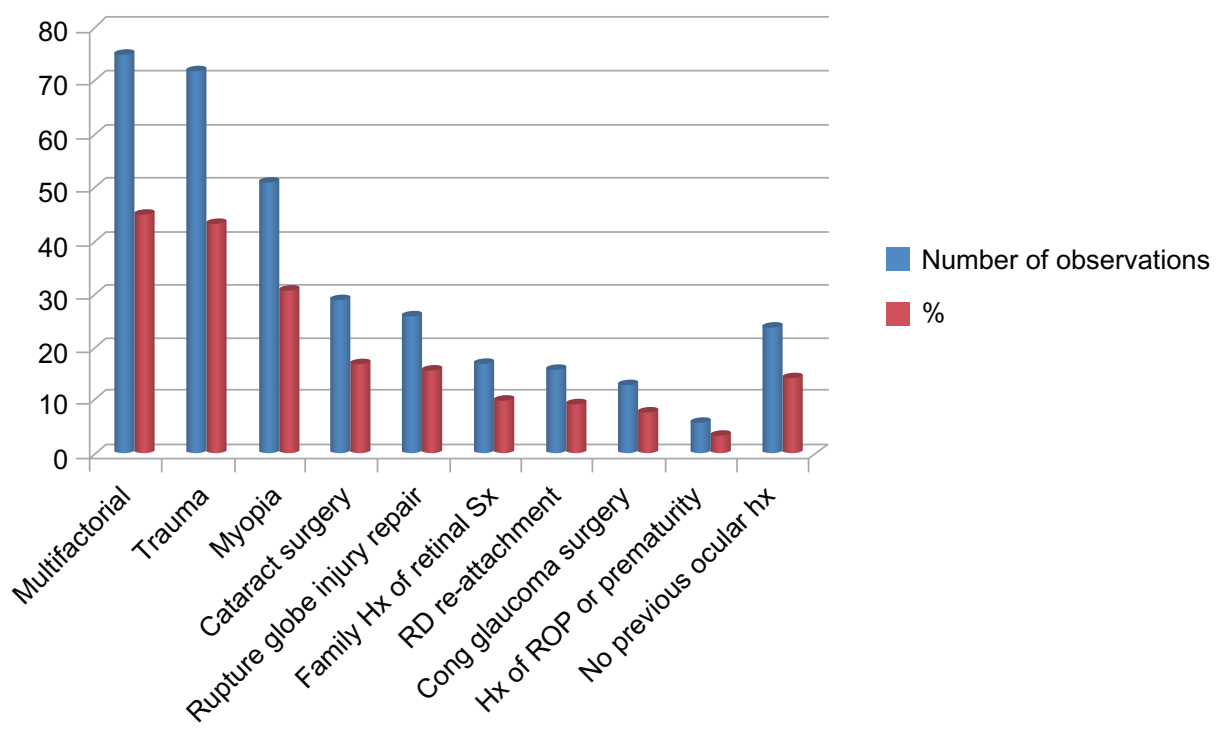

Figure 3 Predisposing factors of rhegmatogenous retinal detachment in children.

Abbreviations: Hx, history; RD, retinal detachment; Sx, surgery; Cong, congenital; ROP, retinopathy of prematurity.

and seven (46.7\%) eyes developed PVR, with six $(86 \%)$ progressing to RRD.

Preoperatively, complete retinal detachment was present in $109(65.4 \%)$ eyes, one-quadrant detachment was present in $20(12 \%)$ eyes, a detachment in two quadrants was present in $17(10 \%)$ eyes, and a detachment in three quadrants was present in 19 (11.7\%) eyes. Macula-off retinal detachments were present in $130(78.35 \%)$ eyes. Lattice degeneration was found in $18(10.8 \%)$ eyes (Figure 7$)$.

PVR at presentation occurred in 55 (33\%) eyes. Eighteen of these eyes $(33 \%)$ were grade $\mathrm{C}$ or worse, and in four eyes the PVR was located in the posterior pole.

The primary (first) surgery was pars plana vitrectomy (PPV) in 141 (85\%) eyes. Twenty-seven (16.26\%) eyes underwent PPV only. PPV combined with encircling band was

Table I Ophthalmic and congenital/developmental associations of rhegmatogenous retinal detachment in children

\begin{tabular}{lll}
\hline Association & Eyes (\%) & Comments \\
\hline Stickler syndrome & $26(15)$ & \\
Jensen's disease & $4(2.4)$ & 2 patients \\
Marfan syndrome & $3(1.8)$ & \\
Down syndrome & I $(0.6)$ & \\
Ehlers-Danlos syndrome & $2(1.2)$ & I patient with bilateral RRD \\
Involuted ROP & IO (6) & \\
Congenital retinoschisis & I $(0.6)$ & \\
Marshall syndrome & I $(0.6)$ & \\
Retinitis pigmentosa & I $(0.6)$ \\
Choroidal coloboma & $5(3)$ & \\
Schwartz's syndrome & I $(0.6)$ & \\
Hypotony, retinal and & I $(0.6)$ \\
choroidal detachment &
\end{tabular}

Abbreviations: RRD, rhegmatogenous retinal detachment; ROP, retinopathy of prematurity. performed in 114 eyes ( $80 \%$ of eyes that underwent PPV and $68 \%$ of the total primary procedures). Buckling procedures alone as primary surgery were performed in 19 (11.5\%) eyes, seven $(4.2 \%)$ eyes underwent an encircling band procedure only, nine $(5.4 \%)$ eyes underwent band and segmental buckle, and three (1.8\%) eyes underwent a segmental buckle only. Six patients with localized RRD were treated by either laser alone (three $[1.8 \%]$ eyes) or cryotherapy alone (three [1.8\%] eyes). Subretinal fluid drainage was performed in three (1.8\%) eyes, and $27(16.3 \%)$ eyes underwent a retinectomy (Figure 8).

Silicone oil intravitreal tamponade during primary surgery was performed in $96(57.8 \%)$ eyes, and gas (C3F8 or SF6) tamponade was performed in 48 (28.8\%) eyes, including two $(1.2 \%)$ eyes that underwent a buckling procedure and an injection of a gas bubble (Figure 9).

Intraoperatively, the retina was completely flattened in 156 eyes (ten operative reports did not note retinal status). Retinal reattachment after the first procedure occurred in 106 (63.8\%) eyes. Overall, retinal reattachment after multiple surgeries occurred in 134 (80.4\%) eyes. (Figure 10).

Postoperative complications (Figure 11) after the first retinal reattachment surgery occurred in 107 (64.46\%) eyes. Postoperatively, recurrent RRD was present in 60 (36\%) eyes, of which PVR was the cause in 40 (24\%) eyes; eleven $(6.6 \%)$ eyes with postoperative PVR did not have PVR preoperatively. Postoperative cataract was present in $17(10 \%)$ eyes, and glaucoma in 28 (17\%) eyes (three eyes had undergone previous glaucoma surgery). Postoperatively, epiretinal membranes were present in 25 (15\%) eyes; in twelve $(7.2 \%)$ of these eyes, the membranes were part of 


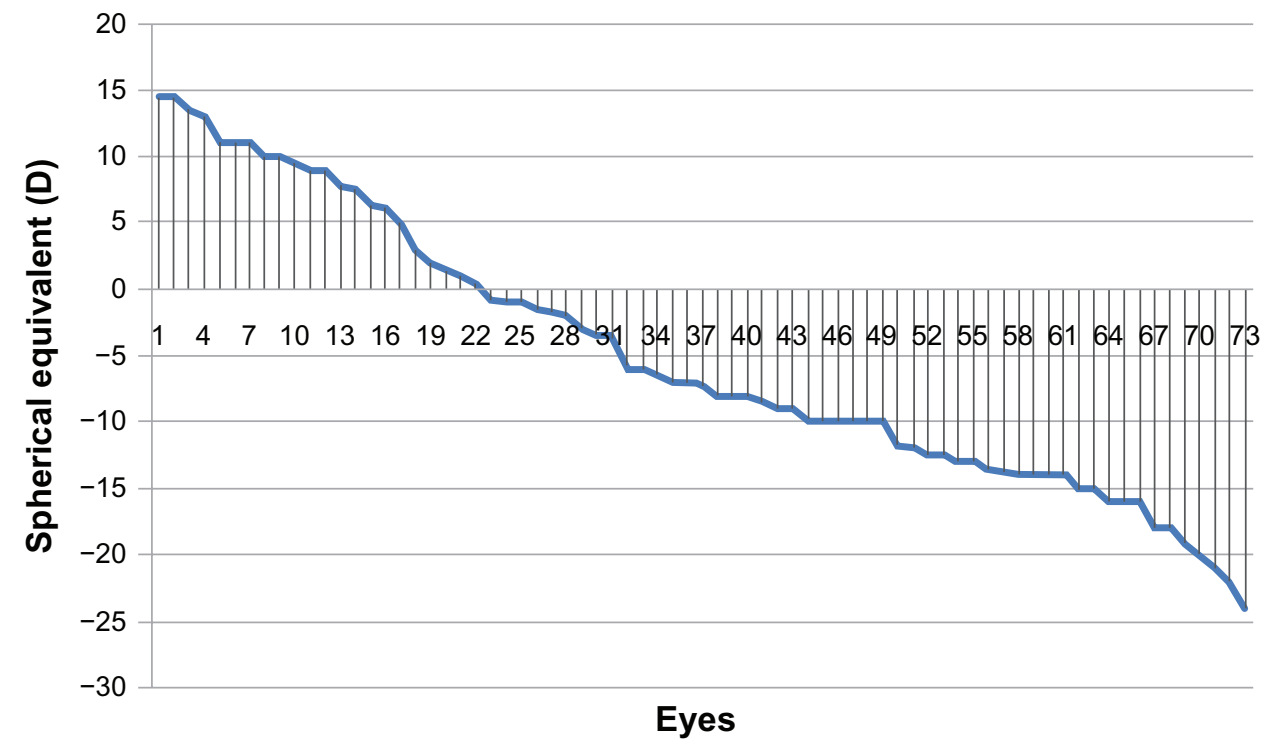

Figure 4 Manifest refractive spherical equivalent in children with rhegmatogenous retinal detachment.

PVR. Postoperatively, seven (4.2\%) eyes had a macular scar, three $(1.8 \%)$ eyes had a corneal scar, and six $(3.6 \%)$ eyes became phthisical.

Modalities to treated postoperative glaucoma included medical therapy (topical drops) for ten (6\%) eyes, surgical intervention for two $(1.2 \%)$ eyes, and medical and surgical intervention for $16(9.6 \%)$ eyes. Surgical management for glaucoma included cyclophotocoagulation, removal of silicone oil when indicated, and tube or filtering procedures. Lensectomy was performed during the primary procedure (PPV) in 85 (51.2\%) eyes. Of these eyes, 40 (24.1\%) had cataract, six (3.6\%) had a subluxated lens, two (1.2\%) had phacodonesis, one $(0.6 \%)$ had a lens coloboma, and 32 $(19.3 \%)$ had a clear physiologic lens preoperatively.

The outcomes of univariate analysis for predisposing factors for recurrence of RRD after the first reattachment surgery are presented in Table 2. Predictors of recurrence after successful primary surgery were myopia $(P=0.028)$, PVR at presentation $(P=0.024)$, and total RRD rather than partial RRD $(P=0.032)$.

Predictors of good final VA $(\geq 20 / 200)$ included good initial vision $(P<0.001)$, absence of PVR at presentation $(P<0.001)$, one-quadrant RRD $(P=0.005)$; macula on $(P=0.0107)$, absence of primary globe repair $(P=0.0059)$,

\section{Myopia group}

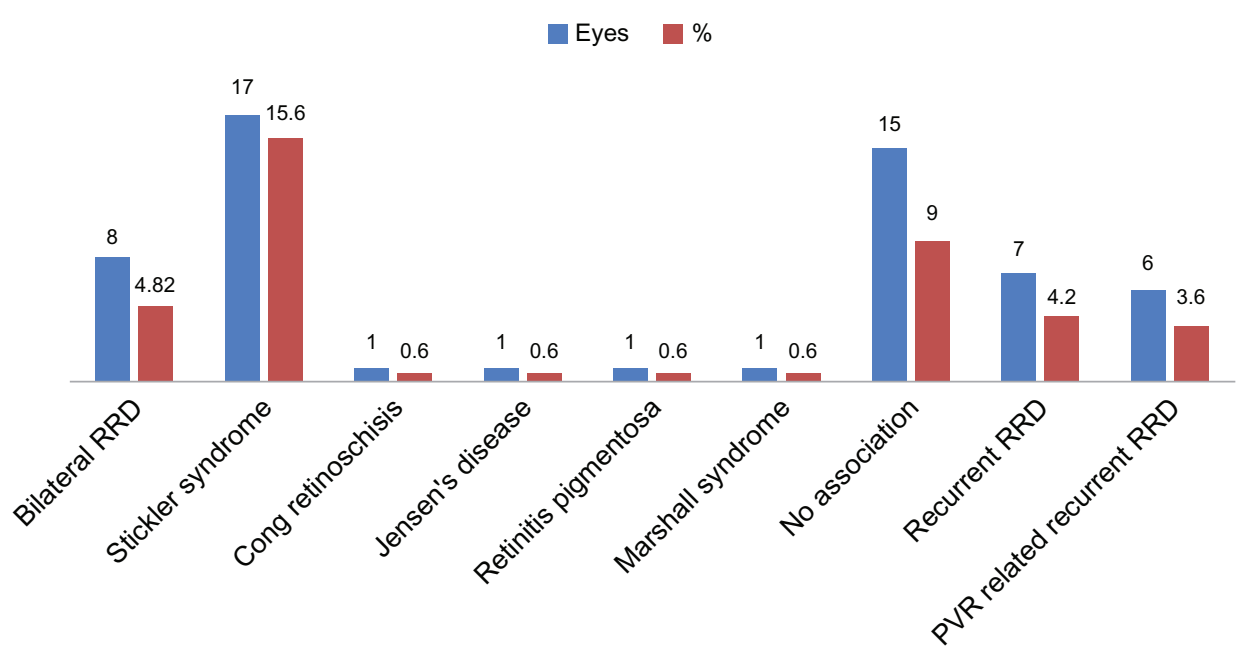

Figure 5 Features of rhegmatogenous retinal detachment in myopic children. Abbreviations: RRD, rhegmatogenous retinal detachment; PVR, proliferative vitreoretinopathy. 


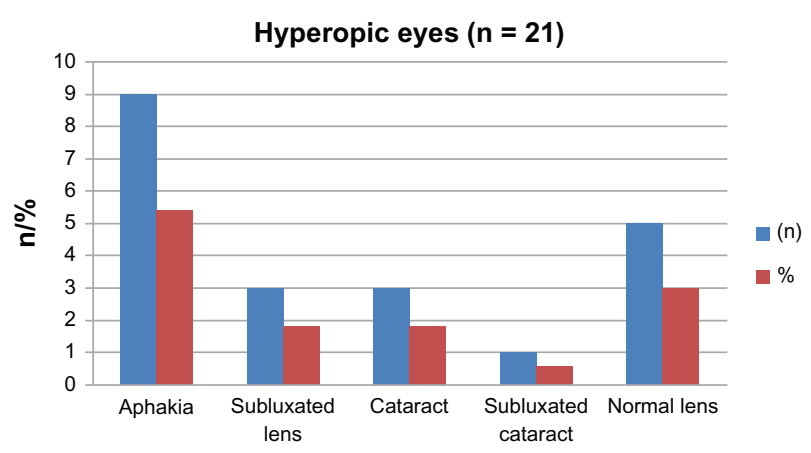

Figure 6 Lens status in hyperopic children.

no PPV $(P=0.0123)$, and clear phakic lens postoperatively $(P<0.001)$ (Table 3$)$. Predictors of poor final VA included poor vision at presentation $(P=0.0033)$, total RRD $(P=0.0479)$, macular involvement $(P=0.0229)$, PPV $(P=0.0115)$, and macular scarring $(P=0.0204)$ (Table 3).

Comparison of initial and final VA is presented in Table 4. Paired data were available on 135 eyes. Sixty-eighty (50.4\%) eyes had no change in VA from preoperatively to postoperatively (Table 3$)$. VA improved in $46(34.1 \%)$ eyes (Table 3). VA decreased in 21 (15.5\%) eyes postoperatively (Table 3). There was a statistically significant increase in the prevalence of $20 / 200$ or better VA from $23.7 \%$ at presentation to $44.4 \%$ of eyes at last follow-up ( $P=0.0031$, Student's $t$-test for two proportions of the same sample). The prevalence of worst vision of HM-LP/NLP decreased from $37.3 \%$ of eyes at presentation to of $27.4 \%$ eyes at last follow-up $(P=0.195)$.

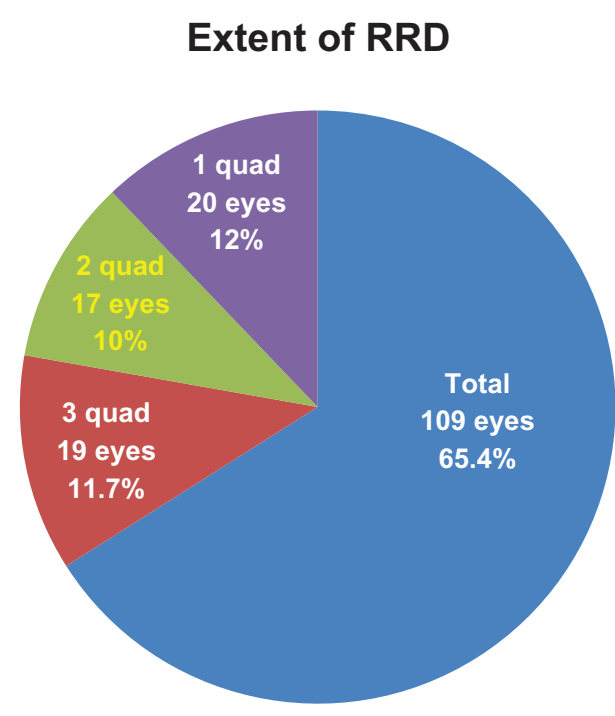

Multivariate stepwise logistic regression analysis indicated variables associated with recurrence of RRD after first surgery and for good final VA. Recurrence of RRD was associated with cataract surgery $(\mathrm{OR}=3.25,95 \% \mathrm{CI} 0.95-11.1)$ and myopia $(\mathrm{OR}=2.1995 \% \mathrm{CI} 1.06-4.56)$. For good final VA $(\geq 20 / 200)$, the positive predictor was macula on (OR $=7.13$, 95\% CI 1.55-32.9), and negative predictors were globe repair $(\mathrm{OR}=0.043,95 \%$ CI $0.006-0.312)$, recurrence of $\mathrm{RRD}(\mathrm{OR}=0.124,95 \% \mathrm{CI} 0.039-0.398)$, and postoperative complications $(\mathrm{OR}=0.40995 \%$ CI $0.149-1.13)$.

\section{Fellow eye}

Sixty-nine (41.4\%) fellow eyes were free of ocular pathology at presentation, and 97 (58.6\%) eyes had multiple pathologies. At presentation, retinal detachment was documented in $47(28.2 \%)$ eyes. These detachments were deemed inoperable in 16 eyes (9.6\%); the remaining 13 eyes $(7.8 \%)$ were included in this study. Four eyes had coloboma components, and six eyes had lattice degeneration, with one associated with a giant tear. Five eyes showed myopic changes, and two eyes were microphthalmic, one associated with coloboma and one with pseudo-retinitis pigmentosa. Retinitis pigmentosa associated with RRD was documented in one eye. X-linked retinoschisis was present in two eyes, vitreoretinal degeneration was present in one eye, white without pressure in one eye, empty vitreous in two eyes, one of which was associated with a giant-tear inoperable RRD, and cystic changes were found in two eyes, one of them associated with a break.

Nine fellow eyes had retinal reattachment surgeries documented on presentation. One eye had a history of recurrent

\section{Total RRD $65.4 \%$ \\ 3 quadrants $11.7 \%$ \\ 2 quadrants $10 \%$ \\ 1 quadrant $12 \%$}

Macula OFF 130 eyes $(78.35 \%)$

PVR @ presentation 55 eyes (33\%) Lattice degeneration 18 eyes (10.8\%) Bilateral RRD (25\%)

Figure 7 Presenting retinal features of the affected eye of children with rhegmatogenous retinal detachment. Abbreviations: RRD, rhegmatogenous retinal detachment; PVR, proliferative vitreoretinopathy. 


\section{Surgical procedure}

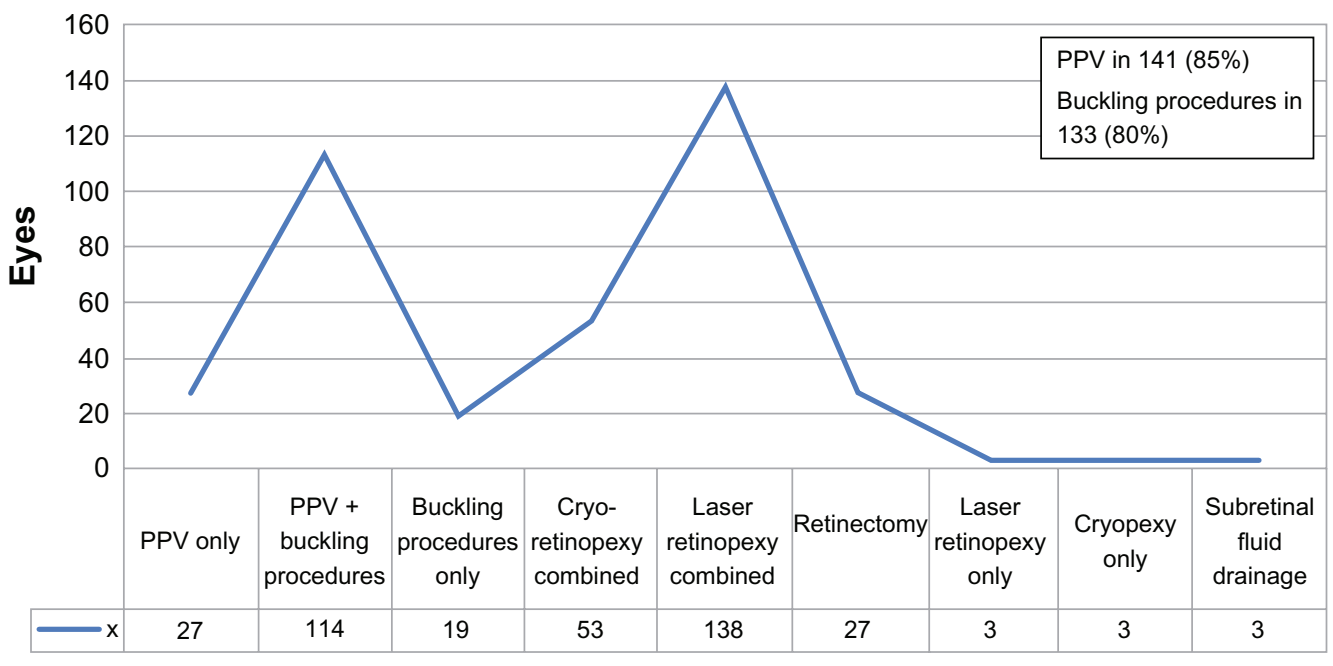

Figure 8 Primary (first) surgical intervention in children with rhegmatogenous retinal detachment.

Note: PPV in I4I (85\%). Buckling procedures in I 33 (80\%).

Abbreviation: PPV, pars plana vitrectomy.

tractional RD. Tears/holes were found in 17 fellow eyes (multiple breaks in four eyes, atrophic holes in one eye, one found to have a break and one with open holes, horseshoe tear found in one eye). Two giant tears (as above) were observed, one of them associated with lattice degeneration and one with empty vitreous. Three eyes underwent glaucoma surgeries; one had NLP vision, and one fellow eye was eviscerated.

\section{Discussion}

In this study of RRD in children, we found the majority of fellow eyes (approximately $60 \%$ ) were also affected and could be treated early. We found a preponderance of males $(70 \%)$ compared to females in the current study. This observation is consistent with previous studies that reported between $60 \%$ and $80 \%$ of males with RRD compared to females. ${ }^{5,11,12}$

\section{Tamponade-143 eyes}

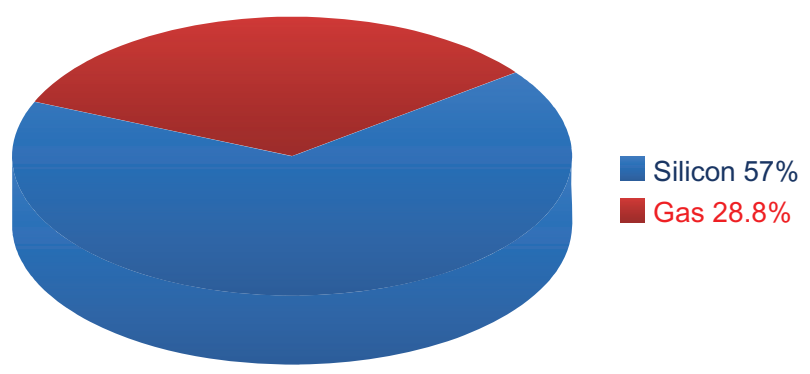

Figure 9 Intraocular tamponade.

Note: 14 I pars plana vitrectomy + two cases had only buckle and gas injection.
Separate studies by Yokoyama et $\mathrm{al}^{8}$ and Weinberg et $\mathrm{al}^{9}$ reported even higher rates of $86 \%$ and $97 \%$, respectively. Differing enrollment criteria such as age and much smaller study sample sizes compared to our study may account for the differences in gender preponderance in our study compared to the two previous studies ${ }^{8,9}$ In the trauma group, $70 \%$ were males in our study, which is similar to the $80 \%$ male figure in the trauma group reported by Winslow and Tasman. ${ }^{2}$ The greater number of males in the trauma group is likely a result of greater risk-taking behavior in male children compared to females.

The presenting symptoms of RRD in children differ in nature from adult RRD. For example, pediatric patients may not be able to complain of decreased vision or loss of vision, and a significant number tend to be discovered incidentally due to chronic retinal detachments. In the current study, the most common presenting symptoms were a decrease or loss

\section{Surgical procedures needed to flatten the retina}

Re-attachment achievement

From single surgery $=63.8 \%$

Eyes $(n)$

Overall $=80.4 \%$

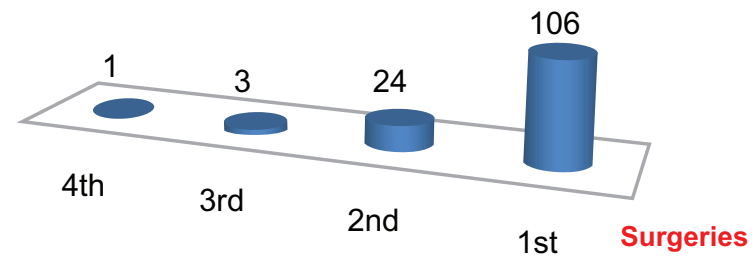

Figure 10 Number of surgeries required to flatten the retina in children with rhegmatogenous retinal detachment. 


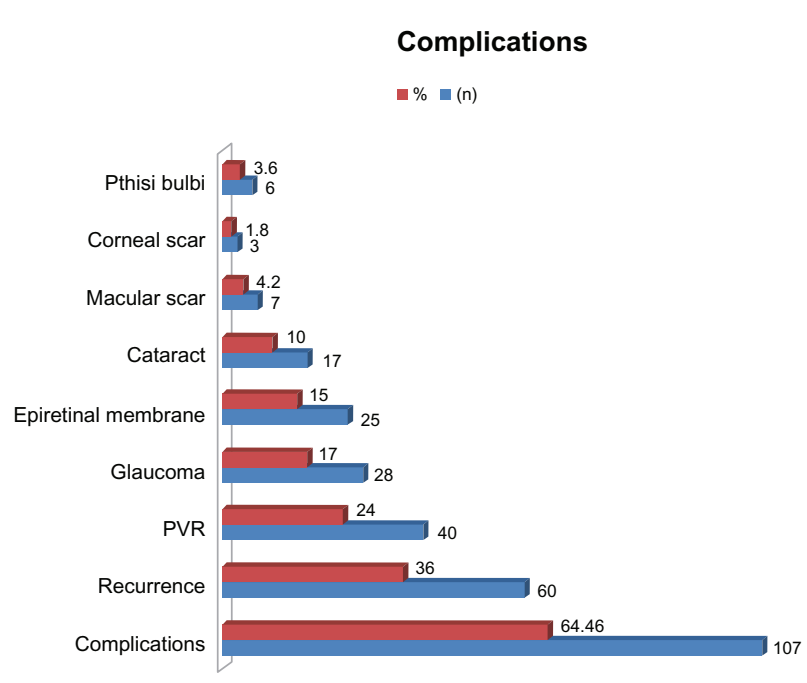

Figure I I Rates of complications in children who underwent retinal reattachment surgery for rhegmatogenous retinal detachment.

Notes: Twelve patients had preoperative PVR; three patients had congenital glaucoma surgeries.

Abbreviation: PVR, proliferative vitreoretinopathy.

of vision in $45.7 \%$ of eyes and incidental findings in routine exam or follow-up in 38 eyes (23\%). These outcomes concur with previous literature. Fivgas and Capone ${ }^{7}$ found the most frequent presenting symptom was poor vision (62\%). Wang et $\mathrm{al}^{14}$ reviewed 278 patients and found blurring of vision was the most common complaint. Gonzales et $\mathrm{al}^{37}$ reported that $46 \%$ of patients have presenting symptoms pointing to RD.

The general consensus in the published literature is that trauma, myopia, previous ophthalmic procedures, and congenital or developmental anomalies play a major role in the etiology of RRD in children. ${ }^{5-7,10-12,21-23,35-38}$ Idiopathic or unknown cause of detachment is still a common finding in most studies. Classification as idiopathic disease could be because this age-group does not expresses the full features of the commonly associated diseases, could be related to an unwitnessed blunt trauma, or there is really is no predisposing factor. Strong evidence that there is an underlying etiology is the observation that the vast majority of cases have retinal breaks or holes found intraoperatively (in $86.75 \%$ of eyes in the current study). Additionally, if the patient had no ocular history prior to presentation, there may be at least one predisposing factor elicited via a complete examination. In the current study, eight (4.8\%) eyes had no associated predisposing factor preoperatively. Of these eyes, one had a macular hole, another eye had a giant tear, two eyes had associated cataract changes, and one eye had peripheral degenerative and cystic changes in the fellow eye. Hence, only three (1.8\%) of patients had an uncertain etiology of RRD. The low rate of idiopathic RRD in our study is
Table 2 Risk of recurrence of rhegmatogenous retinal detachment

\begin{tabular}{|c|c|c|}
\hline Risk factor & $\begin{array}{l}\text { Recurrent retinal } \\
\text { detachment } \\
\text { ( } n=60 \text { eyes) }\end{array}$ & $P$-value \\
\hline \multicolumn{3}{|l|}{ Sex } \\
\hline Male $(n=117)$ & $4 \mathrm{I}(35 \%)$ & 0.78 \\
\hline Female $(n=49)$ & $19(38.8 \%)$ & \\
\hline \multicolumn{3}{|l|}{ Age (years) } \\
\hline$\leq 5(n=32)$ & $13(40.6 \%)$ & 0.702 \\
\hline$>5(n=134)$ & $47(35.1 \%)$ & \\
\hline \multicolumn{3}{|l|}{ Laterality } \\
\hline Unilateral $(n=115)$ & $4 \mathrm{l}(35.7 \%)$ & 0.981 \\
\hline Bilateral $(n=5 I)$ & $19(37.3 \%)$ & \\
\hline \multicolumn{3}{|c|}{ Duration of symptoms, "missing 63" } \\
\hline$<6$ weeks $(n=35)$ & $9(25.7 \%)$ & 0.364 \\
\hline$\geq 6$ weeks $(n=68)$ & $25(36.8 \%)$ & \\
\hline \multicolumn{3}{|l|}{ Trauma } \\
\hline Yes $(n=64)$ & $20(31.3 \%)$ & 0.382 \\
\hline No $(n=102)$ & $40(39.2 \%)$ & \\
\hline \multicolumn{3}{|l|}{ Ruptured globe repair } \\
\hline Yes $(n=25)$ & $9(36.0 \%)$ & 0.999 \\
\hline No $(n=|4|)$ & $51(36.2 \%)$ & \\
\hline \multicolumn{3}{|c|}{ Type of globe injury, "missing 98" } \\
\hline Open $(n=28)$ & $9(36.0 \%)$ & 0.999 \\
\hline Closed $(n=40)$ & $12(30.0 \%)$ & \\
\hline \multicolumn{3}{|l|}{ Past ocular history } \\
\hline \multicolumn{3}{|l|}{ Congenital cataract } \\
\hline Yes $(n=12)$ & $7(58.3 \%)$ & 0.122 \\
\hline No $(n=154)$ & $53(34.4 \%)$ & \\
\hline \multicolumn{3}{|l|}{ Congenital glaucoma } \\
\hline Yes $(n=16)$ & $7(43.8 \%)$ & 0.695 \\
\hline No $(n=150)$ & $53(35.3 \%)$ & \\
\hline \multicolumn{3}{|l|}{ Myopia } \\
\hline Yes $(n=48)$ & $24(50.0 \%)$ & $0.028 *$ \\
\hline No $(n=118)$ & $36(30.5 \%)$ & \\
\hline \multicolumn{3}{|c|}{ Visual acuity at presentation, "missing 27" } \\
\hline HM-LP/NLP $(n=53)$ & $23(43.4 \%)$ & 0.227 \\
\hline$C F(n=54)$ & $21(38.9 \%)$ & \\
\hline$\geq 20 / 200(n=32)$ & $8(25.0 \%)$ & \\
\hline \multicolumn{3}{|c|}{ PVR at presentation, "missing 26 " } \\
\hline Yes $(n=54)$ & $26(48.1 \%)$ & $0.024 *$ \\
\hline No $(n=86)$ & $24(27.9 \%)$ & \\
\hline \multicolumn{3}{|c|}{ Extent of retinal detachment (in quadrants), "missing 4" } \\
\hline$I(n=22)$ & $4(18.2 \%)$ & $0.032 *$ \\
\hline $2-3(n=35)$ & II (31.4\%) & \\
\hline Total (105) & 45 (42.9\%) & \\
\hline \multicolumn{3}{|l|}{ Chronicity } \\
\hline Acute $(n=4 I)$ & II (26.8\%) & 0.255 \\
\hline Chronic $(n=101)$ & $39(38.6 \%)$ & \\
\hline \multicolumn{3}{|l|}{ Macula } \\
\hline On $(n=23)$ & $5(21.7 \%)$ & 0.188 \\
\hline Off $(n=143)$ & $55(38.5 \%)$ & \\
\hline \multicolumn{3}{|c|}{ Lens at presentation, "missing 5" } \\
\hline WNL $(n=79)$ & $25(31.6 \%)$ & 0.2079 \\
\hline Cataract $(n=47)$ & 19 (40.4\%) & \\
\hline
\end{tabular}

(Continued) 
Table 2 (Continued)

\begin{tabular}{|c|c|c|}
\hline Risk factor & $\begin{array}{l}\text { Recurrent retinal } \\
\text { detachment } \\
(n=60 \text { eyes })\end{array}$ & $P$-value \\
\hline Aphakia/pseudophakia $(n=26)$ & $12(46.2 \%)$ & \\
\hline Dislocated/subluxated $(n=9)$ & I (II.I\%) & \\
\hline \multicolumn{3}{|l|}{ Preoperative IOP, "missing 50” } \\
\hline$\leq 5 \mathrm{mmHg}(\mathrm{n}=9)$ & $2(22.2 \%)$ & 0.719 \\
\hline$>5 \mathrm{mmHg}(\mathrm{n}=107)$ & $34(31.8 \%)$ & \\
\hline \multicolumn{3}{|l|}{ Tear/hole multiple, "missing I5" } \\
\hline Yes $(n=37)$ & $14(37.8 \%)$ & \\
\hline No $(n=114)$ & $40(35.1 \%)$ & \\
\hline \multicolumn{3}{|l|}{ Surgical procedures } \\
\hline \multicolumn{3}{|l|}{ Pars plana vitrectomy } \\
\hline Yes $(n=138)$ & $54(39.1 \%)$ & 0.118 \\
\hline No $(n=28)$ & $6(21.4 \%)$ & \\
\hline \multicolumn{3}{|l|}{ Encircling band with PPV } \\
\hline Yes $(n=112)$ & $40(35.7 \%)$ & 0.138 \\
\hline No $(n=26)$ & $14(53.8 \%)$ & \\
\hline \multicolumn{3}{|l|}{ Peeling of posterior hyaloid } \\
\hline Yes $(n=92)$ & $39(42.4 \%)$ & 0.088 \\
\hline No $(n=74)$ & $2 \mathrm{I}(28.4 \%)$ & \\
\hline \multicolumn{3}{|l|}{ Tamponade used } \\
\hline Gas $(n=48)$ & $16(33.3 \%)$ & 0.3517 \\
\hline Silicone oil $(n=93)$ & $40(43.0 \%)$ & \\
\hline \multicolumn{3}{|l|}{ Intraoperative complications } \\
\hline Yes $(n=20)$ & $8(40.4 \%)$ & 0.893 \\
\hline No $(n=146)$ & $52(35.6 \%)$ & \\
\hline
\end{tabular}

Note: $* P<0.05$.

Abbreviations: n, number of eyes; missing, data was not available; HM, hand motions; CF, counting fingers; PVR, proliferative vitreoretinopathy; IOP, intraocular pressure; PPV, pars plana vitrectomy; WNL, within normal limits.

similar to that reported by Wang et al,${ }^{14}$ who found $4.7 \%$ of 296 eyes with no predisposing factor. Similarly, Gonzales et $\mathrm{a}^{37}$ found underlying retinal conditions in $98 \%$ of the 46 eyes they evaluated.

We found almost half the eyes (43.3\%) had a previous history of trauma. This observation is similar to previous studies that reported between $42 \%$ and $45 \%$ of eyes with RRD had a history of trauma. ${ }^{2,7,33,37}$ The highest rate of eyes with RRD with a history of trauma is $53 \% .{ }^{36}$ However, lower rates than ours have been reported for eyes with RRD with a history of trauma ranging from $22 \%$ to $36 \%{ }^{3,9,11,14,16}$ Differences in the sample size, sex ratios (females prone to more risk-averse behavior), and enrollment criteria likely explain the differences between our study and studies reporting a lower history of trauma. Of note, even with the lowest rate of $22 \%$, trauma is clearly a significant factor for RRD in children.

Over half (50.6\%) of eyes with RRD had undergone previous ophthalmic surgery in the current study. This observation falls well within the range reported by previous studies of $34 \%$ to $60 \%{ }^{9,7,37}$ However, Yokoyama et al, ${ }^{8}$ Wang et al, ${ }^{14}$ and Chang et $\mathrm{al}^{16}$ reported much lower rates of $2 \%, 5 \%$, and
$6 \%$, respectively. Similar to trauma, differences in the sample size, sex ratios (females prone to more risk-averse behavior), and enrollment criteria likely explain the differences between our study and the previous three studies. ${ }^{8,14,16}$

Thirty-one percent of the patients in the current study had developmental or ophthalmic/systemic associations with $\mathrm{RRD}$. There is a wide variation in the reported association of developmental, ophthalmic, or system association that varies between $3.3 \%$ and $56 \%$., $3,4,8,14,16,33,37$ This wide range is due to the diversity in defining these variables. For example, some studies include myopia and Stickler syndrome, whereas others class them separately. We included all the contributing developmental or congenital ophthalmic or systemic associations in one group. The variation in outcomes of our study and previous studies indicated further investigation is required with strictly established criteria of developmental, ophthalmic, or systemic associations with RRD.

Thirty percent of eyes in the current study had myopia, which is within the range of previous studies $(20 \%-38 \%))^{7,11,14}$ In 1978, Winslow and Tasman ${ }^{2}$ reported $15 \%$ of 179 eyes with myopia. Similar to our study, Winslow and Tasman evaluated children 16 years of age or younger. A more recent study by Gonzales et a ${ }^{37}$ reported $17 \%$ of children with RRD had myopia as a predisposing factor. In the current study, isolated myopia accounted for only $9 \%$ of eyes with RRD. The refractive error ranged from -6 to $-24 \mathrm{D}$ (mean $-13.1 \pm 4.49 \mathrm{D}$ median $-13 \mathrm{D}$ ).

We found the most common breaks were round holes and tears in $62 \%$ of eyes with RRD. These data concur with Chen et al, ${ }^{11}$ who reported $71 \%$, Butler et $\mathrm{al}^{4}$ who reported $73 \%$, and Akabane et al, ${ }^{3}$ who reported $68 \%$. Retinal dialysis was found in $20.8 \%$ of the eyes with RRD in our study population and in $27 \%$ of the eyes studied by Yokoyama et al. ${ }^{8}$ However, Winslow and Tasman ${ }^{2}$ reported $40 \%$ of eyes with retinal dialysis, and Akabane et $\mathrm{al}^{3}$ reported a rate of $63 \%$. Giant tears were found in $22.9 \%$ of eyes in the current study population, whereas the range in the literature varies from $6.3 \%$ to $15 \%{ }^{3,9,36}$ Posterior breaks were documented in $17.5 \%$ of eyes in the current study and multiple holes/breaks in $22.3 \%$ of eyes. Multiple giant breaks were rare in the current study (1.2\%), and no breaks or holes were identified in twelve eyes (7.22\%). Macular holes were also rare, occurring in only two eyes in the current study.

PPV with or without a buckling procedure (encircling band or segmental buckle or both) was the most common primary surgical procedure ( $85 \%$ of cases) in the current study. Scleral buckle or band as the primary procedure was 
Table 3 Factors affecting final visual acuity

\begin{tabular}{|c|c|c|c|}
\hline \multirow[t]{2}{*}{ Risk factor } & \multicolumn{3}{|l|}{ Final visual acuity } \\
\hline & NLP/LP-HM, n (\%) & CF, n (\%) & $\geq 20 / 200$, n (\%) \\
\hline \multicolumn{4}{|l|}{ Age (years) } \\
\hline$\leq 5(n=25)$ & II (44.0) & $7(28.0)$ & $7(28.0)$ \\
\hline$>5(n=133)$ & $34(25.6)$ & $38(28.6)$ & $61(45.8)$ \\
\hline$P$-value & 0.1026 & 0.999 & 0.1513 \\
\hline \multicolumn{4}{|l|}{ Sex } \\
\hline Male $(\mathrm{n}=\mathrm{III})$ & 31 (27.9) & $35(31.5)$ & $45(40.6)$ \\
\hline Female $(n=47)$ & $14(29.8)$ & $10(2 \mid .3)$ & $23(48.39)$ \\
\hline$P$-value & 0.965 & 0.258 & 0.4245 \\
\hline \multicolumn{4}{|l|}{ Laterality } \\
\hline Unilateral $(n=113)$ & $32(28.3)$ & $34(30.1)$ & $47(4 \mid .6)$ \\
\hline Bilateral $(n=45)$ & $13(28.9)$ & II (24.4) & $21(46.7)$ \\
\hline$P$-value & 0.999 & 0.6071 & 0.6867 \\
\hline \multicolumn{4}{|l|}{ Congenital cataract } \\
\hline Yes $(n=9)$ & $5(55.6)$ & I (II.I) & $3(33.3)$ \\
\hline No $(n=149)$ & $40(26.8)$ & $44(29.6)$ & $65(43.6)$ \\
\hline$P$-value & 0.1197 & 0.4475 & 0.7331 \\
\hline \multicolumn{4}{|l|}{ Congenital glaucoma } \\
\hline Yes $(n=16)$ & $8(50.0)$ & $2(12.5)$ & $6(37.5)$ \\
\hline No $(n=142)$ & $37(26.1)$ & $43(30.2)$ & $62(43.7)$ \\
\hline$P$-value & 0.0751 & $0.240 \mathrm{I}$ & 0.8371 \\
\hline \multicolumn{4}{|l|}{ Myopia $(\geq-6)$} \\
\hline Yes $(n=47)$ & $16(34.0)$ & II (23.4) & $20(42.6)$ \\
\hline No $(n=1 I I)$ & $29(26.2)$ & $34(30.6)$ & $48(43.2)$ \\
\hline$P$-value & 0.415 & $0.467 \mid$ & 0.999 \\
\hline \multicolumn{4}{|l|}{ Exam at presentation } \\
\hline Visual acuity at presentation & \multicolumn{3}{|c|}{ Complete data in initial and final VA was available for I 35 eyes } \\
\hline NLP/LP-HM $(n=49)$ & $21(42.9)$ & $10(20.4)$ & $18(36.7)$ \\
\hline$C F(n=54)$ & $13(24.1)$ & $23(42.6)$ & $18(33.3)$ \\
\hline$\geq 20 / 200(n=32)$ & $3(9.4)$ & $5(15.6)$ & $24(75.0)$ \\
\hline$P$-value & $0.0033^{*}$ & $0.0086^{*}$ & $<0.00$ I* \\
\hline \multicolumn{4}{|l|}{ PVR at presentation } \\
\hline Yes $(n=50)$ & $20(40.0)$ & $18(36.0)$ & $12(24.0)$ \\
\hline No $(n=84)$ & $17(20.2)$ & $20(23.8)$ & $47(56.0)$ \\
\hline$P$-value & 0.0133 & 0.1882 & $<0.00 I^{*}$ \\
\hline \multicolumn{4}{|l|}{ Retinal detachment quadrants } \\
\hline$I(n=22)$ & $4(18.2)$ & $2(9.1)$ & $16(72.7)$ \\
\hline $2-3(n=35)$ & $7(20.0)$ & $10(28.6)$ & $18(5 \mid .4)$ \\
\hline Total $(n=97)$ & $33(34.0)$ & $31(32.0)$ & $33(34.0)$ \\
\hline$P$-value & 0.147 & 0.0969 & $0.0024 *$ \\
\hline Test of linear trend, $P$-value & 0.065 & $0.0479 *$ & $0.0005^{*}$ \\
\hline \multicolumn{4}{|l|}{ Macula on } \\
\hline Yes $(n=23)$ & $5(21.7)$ & $2(8.7)$ & $16(69.6)$ \\
\hline No $(n=135)$ & $40(29.6)$ & $43(31.9)$ & $52(38.5)$ \\
\hline$P$-value & 0.5995 & $0.0229 *$ & $0.0107 *$ \\
\hline \multicolumn{4}{|l|}{ Chronicity } \\
\hline Acute $(n=4 I)$ & $12(29.3)$ & $8(19.5)$ & $21(5 \mid .2)$ \\
\hline Chronic $(n=93)$ & $28(30.1)$ & $27(29.0)$ & $38(40.9)$ \\
\hline$P$-value & 0.999 & 0.3459 & 0.3553 \\
\hline \multicolumn{4}{|l|}{ Duration of symptoms } \\
\hline$<6$ weeks $(n=34)$ & $6(17.6)$ & II (32.4) & $17(50.0)$ \\
\hline$\geq 6$ weeks $(n=65)$ & $12(18.5)$ & $24(36.9)$ & $29(44.6)$ \\
\hline$P$-value & 0.535 & 0.2401 & 0.7325 \\
\hline
\end{tabular}


Table 3 (Continued)

\begin{tabular}{|c|c|c|c|}
\hline \multirow[t]{2}{*}{ Risk factor } & \multicolumn{3}{|l|}{ Final visual acuity } \\
\hline & NLP/LP-HM, n (\%) & CF, n (\%) & $\geq 20 / 200, \mathrm{n}(\%)$ \\
\hline \multicolumn{4}{|l|}{ Ruptured globe repair } \\
\hline Yes $(n=25)$ & $9(36.0)$ & $12(48.0)$ & $4(16.0)$ \\
\hline No $(n=133)$ & $36(27.1)$ & $33(24.8)$ & $64(48.1)$ \\
\hline$P$-value & 0.5051 & $0.0344 *$ & $0.0059 *$ \\
\hline Type of globe injury & \multicolumn{3}{|c|}{ Data is inapplicable in 100 eyes } \\
\hline Open $(n=28)$ & $8(28.6)$ & $12(42.8)$ & $8(28.6)$ \\
\hline Closed $(n=38)$ & $9(23.7)$ & II (28.9) & I 8 (47.4) \\
\hline$P$-value & 0.8698 & 0.3624 & 0.1971 \\
\hline \multicolumn{4}{|l|}{ Preoperative IOP, $\mathrm{mmHg}$} \\
\hline$\leq 5(n=9)$ & $3(33.4)$ & $2(22.2)$ & $4(44.4)$ \\
\hline$>5(n=103)$ & $23(22.3)$ & $31(30.1)$ & $49(47.6)$ \\
\hline$P$-value & 0.4311 & 0.999 & 0.999 \\
\hline \multicolumn{4}{|l|}{ Multiple tear/hole } \\
\hline Yes $(n=36)$ & $10(27.8)$ & $10(27.8)$ & $16(44.4)$ \\
\hline No $(n=108)$ & $30(27.8)$ & 31 (28.7) & $47(43.5)$ \\
\hline$P$-value & 0.999 & 0.999 & 0.999 \\
\hline \multicolumn{4}{|l|}{ Squint } \\
\hline Yes $(n=24)$ & $6(25.0)$ & $8(33.3)$ & $10(41.7)$ \\
\hline No $(n=68)$ & $17(25.0)$ & $17(245.0)$ & $34(50.0)$ \\
\hline$P$-value & 0.999 & 0.999 & 0.6419 \\
\hline \multicolumn{4}{|l|}{ PPV } \\
\hline Yes $(n=130)$ & $43(33.0)$ & $37(28.5)$ & $50(38.5)$ \\
\hline No $(n=28)$ & $2(7.1)$ & $8(28.6)$ & $18(64.3)$ \\
\hline$P$-value & $0.0115^{*}$ & 0.999 & $0.0123 *$ \\
\hline \multicolumn{4}{|l|}{ Tamponade used } \\
\hline Gas $(n=46)$ & $14(30.5)$ & $10(21.7)$ & $22(47.8)$ \\
\hline Silicon oil $(n=83)$ & $28(33.7)$ & $27(32.6)$ & $28(33.7)$ \\
\hline$P$-value & 0.9225 & 0.2736 & 0.1661 \\
\hline \multicolumn{4}{|l|}{ Encircling band with PPV } \\
\hline Yes $(n=105)$ & $28(26.7)$ & $33(31.4)$ & $44(41.9)$ \\
\hline No $(n=25)$ & $15(60.0)$ & $4(16.0)$ & $6(24.0)$ \\
\hline$P$-value & $0.0032 *$ & 0.1971 & 0.1541 \\
\hline \multicolumn{4}{|l|}{ Lens at last follow-up } \\
\hline Phakic/clear $(n=24)$ & $0(0.0)$ & $4(16.7)$ & $20(83.3)$ \\
\hline Cataract $(n=7)$ & $2(28.6)$ & $4(57.1)$ & I (I4.3) \\
\hline Aphakic $(n=110)$ & $39(35.5)$ & $33(30.0)$ & $38(34.5)$ \\
\hline Pseudophakic $(n=16)$ & $3(18.7)$ & $4(25.0)$ & $9(56.3)$ \\
\hline$P$-value & $0.0046 *$ & 0.2035 & $<0.00 I^{*}$ \\
\hline \multicolumn{4}{|l|}{ Complications } \\
\hline \multicolumn{4}{|l|}{ Postop complications } \\
\hline Yes $(n=100)$ & $43(43.0)$ & $29(29.0)$ & $28(28.0)$ \\
\hline No $(n=58)$ & $2(3.4)$ & $16(27.6)$ & $40(69.0)$ \\
\hline$P$-value & $<0.00 I^{*}$ & 0.9945 & $<0.00 I^{*}$ \\
\hline \multicolumn{4}{|l|}{ Retinal detachment } \\
\hline Yes $(n=56)$ & $32(57.1)$ & $17(30.4)$ & $7(12.5)$ \\
\hline No $(n=102)$ & $13(12.7)$ & $28(27.5)$ & 61 (59.8) \\
\hline$P$-value & $<0.001 *$ & 0.8292 & $<0.00 I^{*}$ \\
\hline \multicolumn{4}{|l|}{ Cataract } \\
\hline Yes $(n=17)$ & $5(29.4)$ & $6(35.3)$ & $6(35.3)$ \\
\hline No $(n=|4|)$ & $40(28.3)$ & $39(27.7)$ & $62(44.0)$ \\
\hline$P$-value & 0.999 & 0.5717 & 0.672 \\
\hline
\end{tabular}


Table 3 (Continued)

\begin{tabular}{|c|c|c|c|}
\hline \multirow[t]{2}{*}{ Risk factor } & \multicolumn{3}{|l|}{ Final visual acuity } \\
\hline & NLP/LP-HM, n (\%) & CF, n (\%) & $\geq 20 / 200$, n (\%) \\
\hline \multicolumn{4}{|l|}{ PVR postop } \\
\hline Yes $(n=36)$ & $23(63.8)$ & II (30.6) & $2(5.6)$ \\
\hline No $(n=122)$ & $22(18.0)$ & $34(27.9)$ & $66(54.1)$ \\
\hline$P$-value & $<0.001 *$ & 0.9174 & $<0.00 I^{*}$ \\
\hline \multicolumn{4}{|l|}{ Glaucoma } \\
\hline Yes $(n=28)$ & $5(17.8)$ & $8(28.6)$ & $15(53.6)$ \\
\hline No $(n=130)$ & $40(30.7)$ & $37(28.5)$ & $53(40.8)$ \\
\hline$P$-value & 0.2533 & 0.999 & 0.3027 \\
\hline \multicolumn{4}{|c|}{ Epiretinal membrane } \\
\hline Yes $(n=2 I)$ & $8(38.1)$ & $10(47.6)$ & $3(14.3)$ \\
\hline No $(n=137)$ & $37(27.0)$ & $35(25.6)$ & $65(47.4)$ \\
\hline$P$-value & 0.4303 & 0.0677 & $0.0088^{*}$ \\
\hline \multicolumn{4}{|l|}{ Macular scar } \\
\hline Yes $(n=7)$ & $5(7 \mid .4)$ & I (I4.3) & I (I4.3) \\
\hline No $(n=|5|)$ & $40(26.5)$ & $44(29.1)$ & $67(44.4)$ \\
\hline$P$-value & $0.0204 *$ & 0.674 & 0.2402 \\
\hline
\end{tabular}

Note: $* P<0.05$.

Abbreviations: $n$, number of eyes; NLP/LP-HM, no light perception/light perception - hand motion; CF, counting fingers; PVR, proliferative vitreoretinopathy; PPV, pars plana vitrectomy; postop, postoperative.

uncommon, with only $11.5 \%$ eyes undergoing this procedure. Overall scleral buckling with or without PPV was common ( $78 \%$ of cases) in the current study. We reported the highest rate of PPV as primary surgical procedure for pediatric RRD. This could be due the high incidence of giant tears, dialysis, and associated lens pathology (34\%) at presentation. Scleral buckle seems to be the most common procedure in previous studies. For example, Winslow and Tasman ${ }^{2}$ performed scleral buckle on all their patients. However, this was before the PPV era. Kocaoglan et $\mathrm{al}^{33}$ reported $100 \%$ buckling surgery. Over time, there has been an increasing adoption of PPV. In order of earliest to most recent studies documenting PPV for RRD, Butler et $\mathrm{al}^{4}$ reported $21 \%$ of cases, Yokoyama et $\mathrm{al}^{8}$ reported $24 \%$ of cases, Chang et a ${ }^{16}$ reported $38 \%$ of cases, Soheilian et $\mathrm{al}^{35}$ reported $63 \%$ of cases, and Gonzales et al reported $74 \%$ of cases. ${ }^{37}$ The success rate after the first surgery was $63.8 \%$, which is well within the range reported in previous

Table 4 Comparison of initial and final visual acuity

\begin{tabular}{lllll}
\hline \multirow{2}{*}{ Final VA } & \multicolumn{3}{l}{ Visual acuity at presentation } & \multirow{2}{*}{ Total } \\
\cline { 2 - 4 } & NLP/LP-HM & CF & $\geq \mathbf{2 0 / 2 0 0}$ & \\
\hline$\geq 20 / 200$ & 18 & 18 & 24 & $60(44.4 \%)$ \\
CF & 10 & 23 & 5 & $38(28.1 \%)$ \\
NLP/LP-HM & 21 & 13 & 3 & $37(27.4 \%)$ \\
Total & $39(36.3 \%)$ & $54(40.0 \%)$ & $32(23.7 \%)$ & $135(100.0 \%)$ \\
\hline
\end{tabular}

Notes: The frequencies along the diagonal line represent eyes that had no changes in visual acuity (VA) from preoperatively to postoperatively. Data above the diagonal line indicate an improvement in VA postoperatively. Data below the diagonal line indicate a decrease in VA postoperatively compared to preoperatively.

Abbreviations: NLP, no light perception; LP-HM, light perception-hand motion; $C F$, counting fingers. studies $(25 \%-96 \%){ }^{33,35}$ The final retinal attachment rate was $80.4 \%$, which compares favorably to the $72 \%-96 \%$ reported in previous literature. ${ }^{7,33}$ Reported overall anatomical retinal reattachment is encouraging despite late initial presentation and high rates of macular detachment and PVR at presentation. ${ }^{3,15}$ Vision improved from $20 / 200$ or better at presentation in $23.7 \%$ to $44.4 \%$ at last follow-up visit. This is comparable to previous studies by Soheilian et al, ${ }^{35}$ Akabane et al, ${ }^{3}$ and Wang et al. ${ }^{14}$

We found predictors of recurrence on univariate analysis were myopia $(P=0.028), \mathrm{PVR}$ at presentation $(P=0.024)$, and total RRD $(P=0.032)$ (Table 2$)$. Predictors of good final VA on univariate analysis were presenting VA of $\geq 20 / 200$ $(P<0.001)$, absence of PVR at presentation $(P<0.001)$, and attached macula at presentation $(P=0.0107)$ (Table 3$)$. The negative predictors of final VA were development of complications after first surgery $(P<0.001)$, specifically recurrence of RRD $(P<0.001)$, postoperative PVR $(P<0.001)$, epiretinal membrane $(P<0.001)$, and ruptured globe repair $(P=0.0059)$. Total retinal detachment found statistically significant for final vision of CF $(P=0.0479)$ and also for final visual acuity $\geq 20 / 200(P=0.0005)$. This outcome could be related to the high percentage of total RRD in our series.

Risk factors for poor surgical outcomes have been extensively studied. Winslow and Tasman ${ }^{2}$ found that chronic RRD and the presence of PVR are predictors of poor outcome. Yokoyama et $\mathrm{al}^{8}$ linked poor final outcomes to initial VA and preoperative PVR. Weinberg et $\mathrm{al}^{9}$ found 
that predictors of poor outcome were LP, macula off, need for PPV, PVR grade C or worse, and the use of silicone oil. Wang et $\mathrm{al}^{14}$ found poor surgical outcome was associated with congenital anomalies, previous intraocular surgery, PVR grade $\mathrm{C}$ or worse, macula off, total RRD, and the use of silicone oil. Gonzales et $\mathrm{al}^{37}$ found that poor outcomes were related to younger age, worse initial vision, greater extent of RRD, and grade C PVR or worse. Chang et $a{ }^{16}$ performed logistic regression analysis and reported that nonmyopic RRD, macular involvement, and PVR are risk factors for poor surgical outcomes. The poorer outcome with silicone oil could be related to the severity of the detachment itself, for which silicone is used as a tamponade. ${ }^{9}$ PVR incidence in children is $29.8 \%-37.5 \%$, while in adults it is $5 \%-10 \%$, possibly because of delayed diagnosis. $^{3}$

Our model of logistic regression related recurrence of RRD to congenital cataract surgery and myopia. Logistic regression indicating good final VA was associated with macula-on retinal detachment. Negative predictors were ruptured globe repair, recurrence of RRD, and postoperative complications.

In conclusion, pediatric RRD is a multifactorial condition in which late presentation and recurrence after surgical repair significantly affect both anatomical and visual outcomes. There is a recent trend toward PPV combined with scleral buckling, possibly due to better surgical results in cases that were deemed inoperable in the past. Finally, a good number of patients will have VA better than 20/200 if they undergo timely surgery.

\section{Acknowledgments}

Delia Pilapil, Dustan Kangave, and Rich Bains, for their contribution to data entry and analysis.

\section{Disclosure}

The authors report no financial conflicts in this project. The data were presented in a resident's thesis in June 2009 at the King Khaled Eye Specialist Hospital in Riyadh, Saudi Arabia and in the Saudi Ophthalmology society annual meeting; February 2013, Riyadh, Saudi Arabia.

\section{References}

1. Tassman W. Retinal detachment in children. Trans Am Acad Ophthalmol Otolaryngol. 1967;71:455-460.

2. Winslow RL, Tasman W. Juvenile rhegmatogenous retinal detachment. Ophthalmology. 1978;85:607-618.

3. Akabane N, Yamamoto S, Tsukahara I, et al. Surgical outcomes in juvenile retinal detachment. Jpn J Ophthalmol. 2001;45:409-411.

4. Butler TKH, Kiel AW, Orr GM. Anatomical and visual outcome of retinal detachment surgery in children. Br J Ophthalmol. 2001;85: 1437-1439.
5. Haimann MH, Burton TC, Brown CK. Epidemiology of retinal detachment. Arch Ophthalmol. 1982;100:289-292.

6. Rosner M, Treister G, Belkin M. Epidemiology of retinal detachment in childhood and adolescence. J Pediatr Ophthalmol Strabismus. 1987;24:42-44.

7. Fivgas GD, Capone A Jr. Paediatric rhegmatogenous retinal detachment. Retina. 2001;21:101-106.

8. Yokoyama T, Kato T, Minamoto A, et al. Characteristics and surgical outcomes of paediatric retinal detachment. Eye (Lond). 2004;18: 889-892.

9. Weinberg DV, Lyon AT, Greenwald MJ, Mets MB. Rhegmatogenous retinal detachments in children. Ophthalmology. 2003;110:1708-1713.

10. Hudson JR. Retinal detachments in children. Trans Ophthalmol Soc UK. 1965;85:79-91.

11. Chen SN, Jiunn-Feng H, Te-Cheng Y. Pediatric rhegmatogenous retinal detachment in Taiwan. Retina. 2006;26:410-414.

12. Madanat AS, Mustafa TAA. Pediatric retinal detachment: is it a real clinical challenge Middle East Journal of Family Medicine. 2005;3(3).

13. Go SL, Hoyng CB, Klaver CC. Genetic risk of rhegmatogenous retinal detachment: a familial aggregation study. Arch Ophthalmol. 2005; $123: 1237-1241$.

14. Wang NK, Tsai $\mathrm{CH}$, Chen YP, et al. Pediatric rhegmatogenous retinal detachment in East Asians. Ophthalmology. 2005;112: 1890-1895.

15. Nagpal M, Nagpal K, Rishi P, Nagpal PN. Juvenile rhegmatogenous retinal detachment. Indian J Ophthalmol. 2004;52:297-302.

16. Chang PY, Yang CM, Yang $\mathrm{CH}$, et al. Clinical characteristics and surgical outcomes of pediatric rhegmatogenous retinal detachment in Taiwan. Am J Ophthalmol. 2005;139:1067-1072.

17. Kiffney GT Jr. The eye of the "battered child." Arch Ophthalmol. 1964;72:231-233.

18. Mushin AS. Ocular damage in the battered-baby syndrome. $\mathrm{Br}$ Med J. 1971;3:402-404

19. Ober R. Hemorrhagic retinopathy in infancy: a clinicopathologic report J Pediatr Ophthalmol Strabismus. 1980;17:17-20.

20. Weidenthal DT, Levin DB. Retinal detachment in a battered infant. Am J Ophthalmol. 1976;81:725-727.

21. Levin AV. Ocular manifestations of child abuse. Ophthalmol Clin North Am. 1990;3:249-264.

22. Shukla M, Ahuja OP, Jamal N. Traumatic retinal detachment. Indian J Ophthalmol. 1986;34:29-32.

23. Sadeh AD, Dotan G, Bracha R, Lazar M, Loewenstein A. Characteristics and outcomes of paediatric rhegmatogenous retinal detachment treated by segmental scleral buckling plus an encircling element. Eye (Lond). 2001;15:31-33.

24. Greven CM, Tasman W. Rhegmatogenous retinal detachment following cryotherapy in retinopathy of prematurity. Arch Ophthalmol. 1989;107:1017-1018.

25. Lee JW, Song SG, Park YH. Clinical features and surgical results of rhegmatogenous retinal detachment in children. J Korean Ophthalmol Soc. 2003;44:830-835.

26. Park KH, Hwang JM, Choi MY, Yu YS, Chung H. Retinal detachment of regressed retinopathy of prematurity in children aged 2-15 years. Retina. 2004;24:368-375.

27. Terasaki H, Hirose T. Late-onset retinal detachment associated with regressed retinopathy of prematurity. Jpn J Ophthalmol. 2003;47: 492-497.

28. Jandeck C, Kellner U, Foerster MH. Late retinal detachment in patients born prematurely: outcome of primary pars plana vitrectomy. Arch Ophthalmol. 2004;122:61-64.

29. Stickler GB, Hughes W, Houchin P. Clinical features of hereditary progressive arthro-ophthalmopathy (Stickler syndrome): a survey. Genet Med. 2001;3:192-196.

30. Parke IDW. Stickler syndrome: clinical care and molecular genetics. Am J Ophthalmol. 2002;134:746-748.

31. Ang A, Poulson AV, Goodburn SF, Richards AJ, Scott JD, Snead MP. Retinal detachment and prophylaxis in type I Stickler syndrome. Ophthalmology. 2008;115:164-168. 
32. Abeysiri P, Bunce C, da Cruz L. Outcomes of surgery for retinal detachment in patients with stickler syndrome: a comparison of two sequential 20-year cohorts. Graefes Arch Clin Exp Ophthalmol. 2007;245:1633-1638.

33. Kocaoglan H, Unlü N, Acar MA, Sargin M, Aslan BS, Duman S. The efficacy of conventional rhegmatogenous retinal detachment surgery in the pediatric population. J Pediatr Ophthalmol Strabismus. 2003:40:4-5.

34. Khvatova AV, Zakharova GI, Mosin IM, Kiselev VV. Remote results of surgical treatment rhegmatogenous retinal detachment in children. Vestn Oftalmol. 1997;113:7-12. Russian.

35. Soheilian M, Ramezani A, Malihi M, et al. Clinical features and surgical outcomes of pediatric rhegmatogenous retinal detachment. Retina. 2009;29:545-551.
36. Lee RW, Mayer EJ, Markham RH. The etiology of pediatric rhegmatogenous retinal detachment: 15 years experience. Eye (Lond). 2008;22:636-640.

37. Gonzales CR, Singh S, Yu F, Kreiger AE, Gupta A, Schwartz SD. Pediatric rhegmatogenous retinal detachment: clinical features and surgical outcomes. Retina. 2008;28:847-852.

38. Oono Y, Uehara K, Haruta M, Yamakawa R. Characteristics and surgical outcomes of pediatric rhegmatogenous retinal detachment. Clin Ophthalmol. 2012;6:939-943.
Clinical Ophthalmology

\section{Publish your work in this journal}

Clinical Ophthalmology is an international, peer-reviewed journal covering all subspecialties within ophthalmology. Key topics include: Optometry; Visual science; Pharmacology and drug therapy in eye diseases; Basic Sciences; Primary and Secondary eye care; Patient Safety and Quality of Care Improvements. This journal is indexed on

\section{Dovepress}

PubMed Central and CAS, and is the official journal of The Society of Clinical Ophthalmology (SCO). The manuscript management system is completely online and includes a very quick and fair peer-review system, which is all easy to use. Visit http://www.dovepress.com/ testimonials.php to read real quotes from published authors. 